\title{
Solvency capital requirement and the claims development result
}

\section{Munroe*, B. Zehnwirth and I. Goldenberg}

\begin{abstract}
In this paper, four variants of calculating the Solvency Capital Requirement for long-tail liabilities satisfying Solvency II regulations are discussed. The merits of each metric are related to the stated objectives of Solvency II. Assumptions made in the calculations are assessed for suitability for the determination of an appropriate level of Solvency Capital. We show that two methods for calculating Solvency Capital provide insufficient capital to restore the Economic Balance Sheet in the event of distress. The standard formula referencing the Claims Development Result is shown to be too conservative when models are correctly specified.
\end{abstract}

\section{Keywords}

One-Year Risk Horizon; Risk Margin; Claims Development Result; Variation in Mean Ultimate; Solvency Capital Requirement

\section{Introduction}

Solvency II regulation (European Commission, 2007, 2009b) specifies an insurer should be able to withstand a 1 in 200 years loss and still have sufficient capital for risk to be fairly transferred to a third party. While some example formulae are provided, the onus is on the insurer to demonstrate that a sufficient level of capital is held. Due to the general nature of the specification, there are several measures for calculating the appropriate level of risk capital (Merz \& Wüthrich, 2008; England, 2011; Munroe et al., 2015; and others).

Loss data arrive each calendar year. When new data come in, there are two possibilities:

- the data fall within tolerance of the loss distributions projected by the fitted model and so parameters can be simply reestimated (see also Ohlsson \& Lauzeningks (2009) in respect of algorithm expectations on updating);

- the data call the prior year's parameter-structure into question and the fitted model needs to be revised.

We only consider the first case in this paper since the second requires external input.

Reestimating the fitted model introduces implicit correlations between projected distributions in each subsequent calendar year. Correlations between these projected distributions will be greater than 0 since the data used to estimate any parameter at time $t+1$ includes all the data used to estimate the parameter at time $t$. A high loss at time $t+1$ will increase the parameter estimate at time $t+1$ relative

*Correspondence to: David Munroe, Suite 6\&7, 40-44 St Kilda Road, St Kilda, VIC 3182, Australia. Email: davidmunroe@insureware.com 
to time $t$ and vice versa. The magnitude of the correlation depends on the level of uncertainty in the parameters. The higher the parameter uncertainty, the higher the correlations between successive distributions.

In this paper, we discuss four of these measures for the Solvency II Capital Requirement (SCR) with increasing degrees of complexity. The complexity of the solutions is directly connected to calendar year correlation assumptions. The first three measures were presented in Munroe et al. (2015). The fourth example is a proxy for SCR given in the standard formula (European Commission, 2010, SCR.10.54.) based on the concept of the Claims Development Result (CDR) (Merz \& Wüthrich, 2008; England, 2011). This treatment is intended to bring the crucial issues to the fore.

Two naïve solutions from Munroe et al. (2015) are demonstrably insufficient to truly restore the Economic Balance Sheet to fair value except under very specific conditions. Real world environments are rarely so simple, and in this paper we demonstrate heuristically that the third measure is the most suitable candidate for achieving the Solvency II objectives.

The CDR, as introduced by Merz \& Wüthrich (2008), is commonly used in the Solvency II literature. CDR is the difference between the expected ultimate loss at inception (or at a given time, $t$ ) and the new estimate 1 year later. Over a 1 year time horizon, $C D R$ is said to represent the movement of the Economic Balance Sheet (Merz \& Wüthrich, 2008).

A method for calculating the Solvency II SCR via the CDR has been given as the third standard formula proxy for SCR (European Commission, 2010). Here the standard deviation of the CDR is used to quantify reserve risk. A distribution, such as the log-normal, is assumed where the mean and standard deviation correspond to the expected ultimate loss and standard deviation of the CDR, respectively. The $99.5^{\text {th }}$ percentile of this distribution is the estimate of the SCR.

In this formulation, the CDR is not explicitly conditioned on a distress scenario arising in the next calendar year but rather examines the situation such that the adjustment to the mean ultimate in the next calendar year is a 1 in 200 adjustment. We show that, should the distributional assumptions be known, the $99.5^{\text {th }}$ percentile of the variation in mean ultimate (VMU) is far too conservative a measure of risk capital and does not properly allow for risk diversification between the calendar years.

The four measures of the SCR are related to each other and compared using a few examples.

\section{Solvency II 1-Year Risk Horizon and the Economic Balance Sheet}

There are three basic elements to the Solvency II directives issued by the European Commission (2010) in respect to Risk Capital:

- For the purpose of calculating the risk margin (RM) and understanding the hypothetical flow of capital, it is assumed that Risk Capital is raised at the beginning of each year and any unused capital is returned to the capital provider at the end of the year;

- the analyses are conditional on the first (next) calendar year being in distress (99.5\%);

- at the end of the first year in distress, the balance sheet can be restored in such a way that the company has sufficient Technical Provisions (TPs) (equivalently the Fair Value of Liabilities) to continue business or to transfer the liabilities to another risk bearing entity. 
The Cost of Capital approach is used to calculate the RM for non-hedgeable risks. The $\mathrm{RM}$ represents the premium paid to the notional risk capital providers for providing Risk Capital.

As an insurer must be able to withstand a 1 in 200 year loss and still have sufficient capital for risk to be fairly transferred to a third party (European Commission, 2007, 2009b), it follows that the Best Estimate of Liabilities (BEL) and RM, collectively known as the TP, are the cornerstone of the Solvency II 1-year risk horizon.

$$
\mathrm{TP}=\mathrm{BEL}+\mathrm{RM}
$$

The regulation includes provision to discount TP by the risk-free rate. However, for simplicity the risk-free rate (the present value discount) is omitted from all calculations in this paper.

\section{SCR: A Naïve Definition}

In order to demonstrate that the company has sufficient capital to sustain losses at the $99.5^{\text {th }}$ percentile in the first calendar year the effect of a 1 in 200 year loss in the next calendar year is to be estimated.

The BEL covers the loss up to the best estimate. Only the excess loss, the loss above the mean, is required as risk capital to sustain losses at the $99.5^{\text {th }}$ percentile.

Let $Y$ denote a random variable representing the loss (the reserve).

In the reserving context, the Value-at-Risk $(V @ R)$ is the capital at risk for a quantile, $\alpha \in(0,1)$, given the distribution of losses, $Y$, and the expected loss, $\bar{Y}$.

$$
V @ R_{\alpha}(Y)=F_{Y}^{-1}(1-\alpha)-\bar{Y}
$$

where $F$ is the cumulative distribution function.

Consider a loss reserve distribution as displayed in Figure 1. The vertical bar displays the mean, $699 \mathrm{M}$, of the distribution. The $75^{\text {th }}$ percentile of the distribution is $725 \mathrm{M}$. The difference between the $75^{\text {th }}$ percentile and the mean, $27 M$ (rounding), is the capital that would be lost if the mean reserve

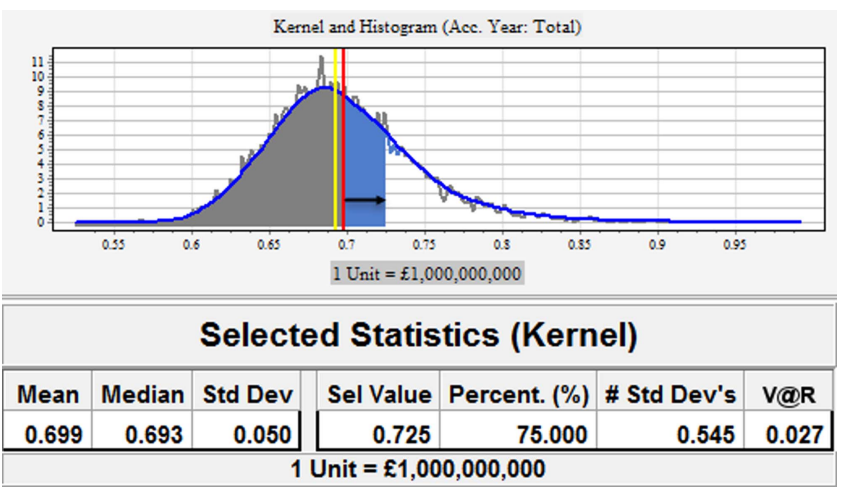

Figure 1. Value-at-risk at $75^{\text {th }}$ percentile for an example distribution. 


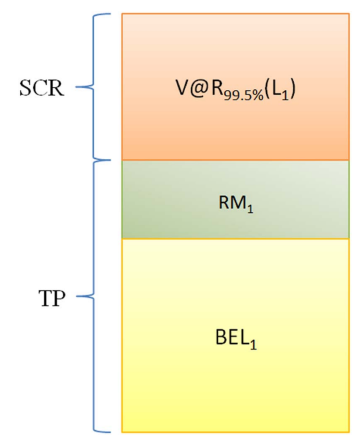

Figure 2. One-year run-off. TP, Technical Provision; SCR, Solvency II Capital Requirement

was booked and the losses actually came in at the $75^{\text {th }}$ percentile of the loss distribution. That is, the $V @ R$ is $27 \mathrm{M}$. The probability of losing at least $27 M$ is $(1-\alpha)$, which is $25 \%$.

There are other measures of $V @ R$ such as Tail $-V @ R$ which calculates the average loss should the loss exceed the percentile, $\alpha$. These alternatives are not considered in the Solvency II context, however they may be used in other solvency regulation (for instance, Swiss Solvency Test Swiss Federal Office of Private Insurance, 2004).

This simple definition of SCR is

$$
S C R^{1}=V @ R_{99.5 \%}\left(L_{1}\right)
$$

where $L_{1}$ is a random variable representing the first future calendar year loss and $V @ R_{99.5 \%}$ is the $99.5^{\text {th }}$ percentile of the V@R.

In this case, the Economic Balance Sheet for 1-year run-off is depicted in Figure 2.

Here, $B E L_{1}$ is the BEL for year 1 , that is

$$
B E L_{1}=E\left(L_{1}\right)
$$

$R M_{1}$ is the $\mathrm{RM}$ allocated for year 1 , that is

$$
R M_{1}=s \cdot V @ R_{99.5 \%}\left(L_{1}\right)
$$

where $s$ is the spread - the return required above the risk free rate as specified in the regulation (European Commission, 2009a), and

$$
T P_{1}=B E L_{1}+R M_{1}
$$

where $T P_{1}$ is the $T P$ (Fair Value) for year $1\left(T P=T P_{1}\right)$.

In the block diagram above, SCR is the Risk Capital raised from the (hypothetical) risk capital providers and $R M_{1}$ is the cost to the insurer for access to this capital.

If the loss exceeds the $B E L_{1}$ the Risk Capital (in this case $S C R^{1}$ ) is drawn on. At the end of the year, the risk capital providers receive the $S C R^{1}$ less the drawn capital.

$R M_{1}$ is paid to the risk capital providers at the end of the year irrespective of the value of the loss. 


\subsection{Extending $S C R^{1}$ to Multiple Year Run-Off}

In the case of multiple years in run-off, equation (6) is generalised to equation (1). Rather than calculating the BEL of the first calendar year, the sum of the mean losses of all future calendar years, years $1,2, \ldots$, $n$, is calculated. Similarly, $R M$ is calculated as the sum of the RMs for all future calendar years.

Note $S C R^{1}$, which depends only on $L_{1}$, is unaffected by broadening the context to include $n$ future calendar years.

$S C R^{1}$ is naïve because it assumes future calendar year loss estimates are unaffected by an unusually high result in year 1 . In other words, it would only satisfy the Solvency II requirement on the assumption that future calendar year correlations are 0 . The correlations can only be zero exactly if there is no parameter uncertainty. In this case, the only source of variation would be the process volatility inherent in the data. The unconditional distributions will then be adequate for complete calculation of risk capital and there is no need to allocate additional funds to update either the $B E L$ or the $R M$. This is the theoretical situation where there is maximum diversification between calendar years and it forms the lower bound of the $S C R^{2}$ and $S C R^{3}$ solutions.

Parameter uncertainty induces correlation between future calendar year loss distributions. Further, calendar year correlations between loss distributions are positive when parameter estimates for a fixed model structure are updated. $S C R^{1}$ fails the third of the Solvency II requirements, unless the boundary case is applicable.

\section{SCR: Including Change in BEL}

Incorporating calendar year correlation leads to an updated definition of SCR. If the first calendar year is in distress, the conditional loss distributions for subsequent years will have higher mean losses.

If the first year is in distress, the adjustments in the mean losses for subsequent years should be part of the Risk Capital raised. This way the BEL can be restored to Fair Value at the beginning of the second calendar year. The business can then continue to operate or the liabilities can be transferred to another risk bearing entity.

We denote the measure including these increments as $S C R^{2}$. This definition is closely related to the definition of the CDR - see section 7. The change in the mean is equivalent to change in own funds when a distress event occurs.

That is

$$
S C R^{2}=S C R^{1}+\sum_{i=2}^{n} \Delta B E L_{i}
$$

where

$$
\triangle B E L_{i}=B E L_{i} \mid\left(L_{1}=\lambda\right)-B E L_{i}
$$

$B E L_{i}$ denotes $E\left(L_{i}\right)$, and $B E L i l\left(L_{1}=\lambda\right)$ is the mean of the conditional distribution of $L_{i}$ (loss in calendar year $i$ ) given that the first year is in distress, that is $\left(L_{1}=\lambda\right)$, where

$$
\lambda=E\left(L_{1}\right)+V @ R_{99.5 \%}\left(L_{1}\right)
$$

and $n$ is the number of future calendar years in the calendar year liability stream. 


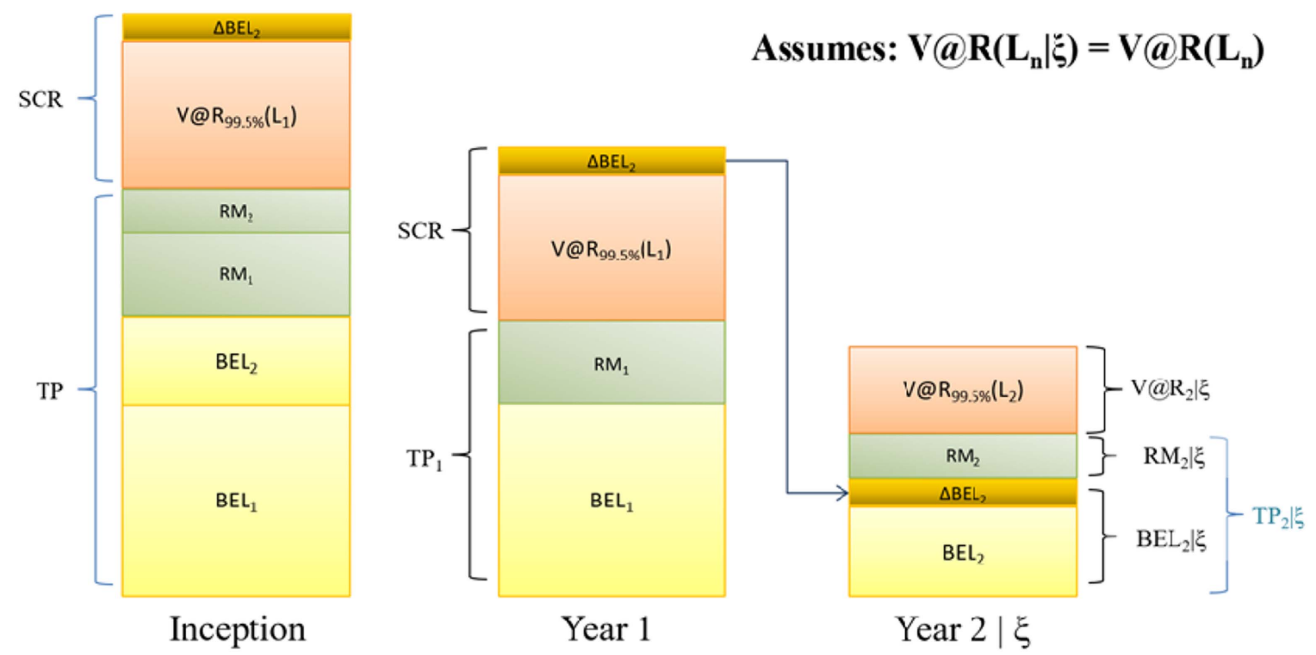

Figure 3. Two-year run-off. TP, Technical Provision; SCR, Solvency II Capital Requirement

The 2 years in run-off case is illustrated in Figure 3. The event that $L_{1}=\lambda$ is designated by $\xi$.

Consider the block diagram in Figure 3.

Given year 1 is in distress, we study year two first.

For the conditional distribution $L_{2} \mid \xi$ the increment in mean (above the unconditional distribution of $\left.L_{2}\right)$ is $\triangle B E L_{2}$.

The event $\xi$ results in (1) drawing on the risk capital for year 1 and (2) re-estimation of BEL at year 2 and hence $S C R^{2}$ is the sum of the V@R plus the $\triangle B E L_{2}$.

The RM, $R M_{1}$, is now based on an SCR that includes $\triangle B E L_{2}$.

The balance sheet at inception contains the sum of the BELs, the sum of the RMs, and the $S C R^{2}$.

The flow of capital should the first year be in distress is as follows:

- $B E L_{1}$ and $V @ R_{99.5 \%}\left(L_{1}\right)$ are consumed;

- $B E L_{2}+\triangle B E L_{2}$ is allocated to year 2 to restore the mean loss to conditional mean;

- $R M_{2}$ is allocated to the RM for year 2;

- $R M_{1}$ is returned to the risk capital provider;

- $R M_{2}$ is left unchanged.

However, should the first year be in distress, it is likely that the $V @ R_{99.5 \%}\left(L_{2} \mid \xi\right)$ will be larger than $V @ R_{99.5 \%}\left(L_{2}\right)$. Let $\Delta R M_{2}$ be the difference between the RM $R M_{2}$ and the RM $R M_{2} \mid \xi$. Additional capital is needed to restore the Economic Balance Sheet to its Fair Value. This is necessary to satisfy the Solvency II objective that the liability risk can be fairly transferred to a third party (European Commission, 2007, 2009b). 
$S C R^{2}$ acknowledges the need for recalculation of future years after a distress year but fails to carry it through to every component of the TP. This leads to $S C R^{3}$.

\section{SCR: Including Change in TP}

Figure 4 includes the increment in RM in year 2 assuming the first year is in distress.

Given year 1 is in distress, the increase in $V @ R_{99.5 \%}\left(L_{2}\right)$ is denoted by $\Delta V @ R_{99.5 \%}\left(L_{2}\right)$. This leads to an increase in the RM for year 2, $\Delta R M_{2}$. The $\Delta R M_{2}$ and $\triangle B E L_{2}$ are both incorporated in the SCR for year 1 allowing the Economic Balance Sheet to be fully restored to its Fair Value at the beginning of year 2 in the event of distress. The cost of capital for holding SCR, $R M_{1}$, is adjusted to include the cost of also holding $\triangle R M_{2}$ and $\triangle B E L_{2}$.

The flow of capital should the first year be in distress is as follows:

$B E L_{1}$ and $V @ R_{99.5 \%}\left(L_{1}\right)$ are consumed;

$B E L_{2}+\triangle B E L_{2}$ is allocated to year two to restore the mean loss to conditional mean;

$R M_{2}+\Delta R M_{2}$ is allocated to the RM for year 2;

$R M_{1}$ is returned to the risk capital provider.

At inception the two $\Delta$ 's are part of the risk capital in year 1 but they are allocated to the TP in year 2 in the distress event.

The definition of $S C R^{3}$ can be appropriately extended to a multiple year run-off as follows:

$$
S C R^{3}=S C R^{2}+\sum_{i=2}^{n} \Delta R M_{i}
$$
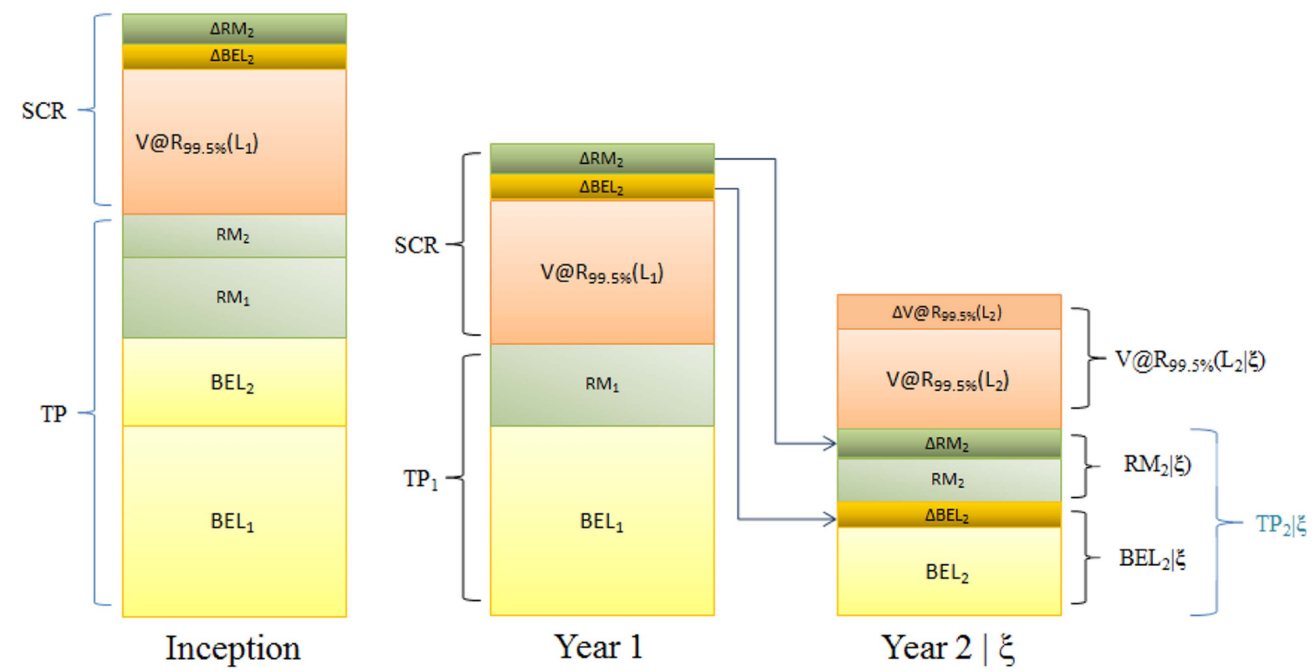

Figure 4. Two-year run-off including $\triangle T P$. TP, Technical Provision; SCR, Solvency II Capital Requirement 
If spread is $0 \%$, then $S C R^{3}=S C R^{2}$. However, the Economic Balance Sheet would then be different as the TP is different.

\section{Variation in the Mean Ultimate Loss 1 Year Hence and the Claims Development Result}

Let's decompose the ultimate loss, $L_{U l t}$, as the sum of the first future year calendar year loss and the sum of subsequent calendar year losses:

$$
L_{U l t}=L_{1}+\sum_{i=2}^{n} L_{i}
$$

Then the expectation of ultimate loss conditional on the first future year loss $E\left(L_{U l t} \mid L_{1}\right)$ is

$$
E\left(L_{U l t} \mid L_{1}\right)=L_{1}+\sum_{i=2}^{n} E\left(L_{i} \mid L_{1}\right)
$$

The quantity

$$
\Delta_{1} L_{U l t}=E\left(L_{U l t} \mid L_{1}\right)-E\left(L_{U l t}\right)
$$

is a random variable dependent on $L_{1}$ that represents the variation in the mean ultimate loss. We denote it by $\operatorname{VMU}\left(L_{1}\right)$ or simply VMU. In the Solvency II literature, $-\Delta_{1} L_{U l t}$ is commonly referred to as the CDR (Merz \& Wüthrich, 2008; England, 2011). The VMU, is a more informative descriptor and under a distress scenario it is positive. (See discussion.)

The expected value of the VMU is 0 . That is

$$
E\left(\Delta_{1} L_{U l t}\right)=E\left(E\left(L_{U l t} \mid L_{1}\right)\right)-E\left(L_{U l t}\right)=0
$$

Taking the variance of the VMU produces the following:

$$
\operatorname{Var}(\operatorname{VMU})=\operatorname{Var}\left(E\left(L_{U l t} \mid L_{1}\right)\right)
$$

which is the same as the variance of the CDR.

This quantity represents the variance of the conditional mean ultimate 1 year hence.

This metric is important for senior management as it contextualises year to year changes in the estimate of mean ultimate. For a model and forecast scenario that are consistent there is statistical variation in the mean ultimate 1 year hence. That is, when a model and forecast scenario are updated with 1 year of new data, forecast scenario assumptions remaining consistent, variation in the mean ultimate is expected. See the example in section 8 .

Indeed, by the law of total variance, $\operatorname{Var}\left(L_{U l t}\right)$ can be decomposed as follows:

$$
\operatorname{Var}\left(L_{U l t}\right)=E\left(\operatorname{Var}\left(L_{U l t} \mid L_{1}\right)\right)+\operatorname{Var}\left(E\left(L_{U l t} \mid L_{1}\right)\right)
$$

The variance of the ultimate is decomposed into two parts. $E\left(\operatorname{Var}\left(L \mid L_{1}\right)\right)$ and the change in the mean ultimate, $\operatorname{Var}\left(E\left(L \mid L_{1}\right)\right)$. Substituting using equation 15 gives:

$$
\operatorname{Var}\left(L_{U l t}\right)=E\left(\operatorname{Var}\left(L_{U l t} \mid L_{1}\right)\right)+\operatorname{Var}(\operatorname{VMU})
$$




$$
\operatorname{Var}(\operatorname{VMU})=E\left(\operatorname{Var}\left(L_{U l t}\right)-\operatorname{Var}\left(L_{U l t} \mid L_{1}\right)\right)
$$

The information acquired when the next year's results are known will reduce the variance of the ultimate. The variation contributed by the first future calendar year is removed (the losses are known), the subsequent parameter uncertainty is lower, and the forecast horizon is shorter. The mean reduction is: $E\left(\operatorname{Var}\left(L_{U l t}\right)-\operatorname{Var}\left(L_{U l t} \mid L_{1}\right)\right)$. By (18) this is the Variance of the VMU.

The proportion of the VMU component is indicative of the sensitivity to the next calendar year's losses. If $\operatorname{Var}(\operatorname{VMU})$ takes a large proportion of the total variance, then the expected ultimate is very sensitive to the losses in the next year. Conversely, if $\operatorname{Var}(V M U)$ takes a low proportion of the total variance then the effects of re-parameterisation after year 1 are swamped by the process volatility. The impact of correlations on the VMU are discussed in section 9.

\section{The Relationship Between the VMU and $S C R^{2}$}

In this section, we show that $\operatorname{VMU}\left(L_{1}=\lambda\right)=S C R^{2}$. Where:

$$
\lambda=E\left(L_{1}\right)+V @ R_{99.5 \%}\left(L_{1}\right)
$$

Now:

$$
\begin{aligned}
V M U & =E\left(L_{U l t} \mid L_{1}\right)-E\left(L_{U l t}\right) \\
& =L_{1}+\sum_{i=2}^{n} E\left(L_{i} \mid L_{1}\right)-E\left(L_{1}\right)-\sum_{i=2}^{n} E\left(L_{i}\right) \\
& =L_{1}-E\left(L_{1}\right)+\sum_{i=2}^{n}\left[E\left(L_{i} \mid L_{1}\right)-E\left(L_{i}\right)\right]
\end{aligned}
$$

Consider VMU when $L_{1}$ is in distress. We can then write:

$$
\begin{aligned}
V M U\left(L_{1}=\lambda\right) & =V @ R_{99.5 \%}\left(L_{1}\right)+\sum_{i=2}^{n}\left[E\left(L_{i} \mid L_{1}=\lambda\right)-E\left(L_{i}\right)\right] \\
& =V @ R_{99.5 \%}\left(L_{1}\right)+\sum_{i=2}^{n} \Delta B E L_{i}
\end{aligned}
$$

Given that calendar year loss correlations are positive, the $\triangle B E L_{i}$ are typically positive:

$$
\operatorname{VMU}\left(L_{1}=\lambda\right)=-\operatorname{CDR}\left(L_{1}=\lambda\right)=S C R^{2}
$$

In the standard formula, one method to calculate the SCR is to calculate the $V @ R_{99.5 \%}(V M U)$.

Calculating the $99.5^{\text {th }}$ percentile of VMU is not equivalent to the realisation of $\operatorname{VMU}\left(L_{1}=\lambda\right)$.

\section{The Distribution of VMU (-CDR)}

In order to find the theoretical distribution of VMU it is necessary to have loss distributions projected by calendar year and their correlations because the measure is inherently linked with calendar time. 
The distributions going forward will depend on the future process volatility, the parameter estimates and their associated uncertainties. Correlations between the calendar year loss distributions are driven by parameter uncertainty. The magnitude of the correlations will also depend on process volatility.

The distribution of VMU is the sum of the conditional means (conditional on the first calendar year) minus the unconditional means: $\sum_{i=2}^{n}\left(E\left(L_{i} \mid L_{1}\right)-E\left(L_{i}\right)\right)$.

The unconditional means, $E\left(L_{i}\right)$, are the mean losses based on the original model. In order to estimate the distribution of VMU, the following steps apply:

1. Use the model to simulate the next calendar year $\left(L_{1}\right)$.

2. Re-estimate the same model, including the data for $L_{1}$, to obtain conditional means $\left(E\left(L_{i} \mid L_{1}\right): i>1\right)$.

For the first calendar year, the difference between the simulated values and the unconditional mean of this year is $\left(L_{1}-E\left(L_{1}\right)\right)$. For subsequent years, $i=2$ to $n$, the $i$ th difference between the conditional means and the unconditional means is $\left(E\left(L_{i} \mid L_{1}\right)-E\left(L_{i}\right)\right)$.

The sums of these differences are realisations of VMU.

To illustrate, assume a model specifies the loss distributions by calendar year as in Table 1 . The total mean outstanding is $7,138,147$ total losses paid to date of $10,221,194$. The corresponding mean ultimate is $17,138,147$.

If we simulate the next calendar year using the model, the distribution of the simulations for that year will have a mean of $1,864,457$ and a SD of 75,213. For each simulation, the model parameters are updated and used to obtain mean projections of the years $E\left(L_{i} \mid \mathrm{L}_{1}\right)$ where $i>1$.

This leads to a distribution for the VMU, $\Sigma_{i=2}^{n}\left(E\left(L_{i} \mid L_{1}\right)-E\left(L_{i}\right)\right)$. One such simulation is shown in Figure 5 .

The $99.5^{\text {th }}$ percentile of the VMU, 581, 656, is highlighted. The distribution of the VMU shows that there is a 1 in 200 probability the current estimate of the mean ultimate, 17, 138, 147, will be

Table 1. Example future calendar year distributions.

\begin{tabular}{lcr}
\hline \hline & Calendar Year Summary \\
\hline Calendar Year & Mean Outstanding & SD \\
\hline 1988 & $1,864,457$ & 75,213 \\
1989 & $1,426,922$ & 65,240 \\
1990 & $1,063,255$ & 55,376 \\
1991 & 796,935 & 47,459 \\
1992 & 604,496 & 40,873 \\
1993 & 470,073 & 35,793 \\
1994 & 363,510 & 30,881 \\
1995 & 273,885 & 25,831 \\
1996 & 182,833 & 19,397 \\
1997 & 91,781 & 11,442 \\
Total & $7,138,147$ & 309,956 \\
& 1 Unit $=1 €$ & \\
\hline \hline
\end{tabular}




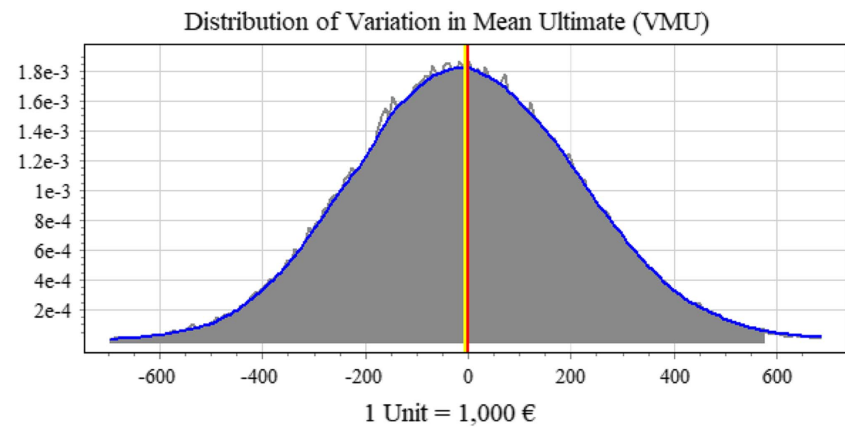

\begin{tabular}{|c|c|c|c|c|c|c|}
\hline \multicolumn{7}{|c|}{ Selected Statistics (Kernel) } \\
\hline Mean & Median & Std Dev & Sel Value & Percent. (\%) & \# Std Dev's & V@R \\
\hline-0.592 & -4.163 & 217.225 & 581.656 & 99.504 & 2.678 & 581.656 \\
\hline
\end{tabular}

Figure 5. Distribution of Variation in Mean Ultimate

increased by at least 581, 656, after next year's losses are realised. See section 10 for the relationship between the VMU at the $99.5^{\text {th }}$ percentile and $S C R^{2}$.

\section{Decomposing the Total Variation of $L_{U l t}$ into $L_{1}$ and $L_{2} \ldots L_{n}$ Given $L_{1}$}

Consider two hypothetical cases where we assess the value of information about the next calendar year's losses. This is discussed in the context of the VMU.

High correlations imply a lot of value in knowing the next calendar year's loss. Low correlations imply knowledge of the next calendar year does not result in knowledge about future calendar years.

$$
\operatorname{Var}\left(E\left[L_{U l t} \mid L_{1}\right]\right)=\operatorname{Var}\left(L_{1}+\sum_{i=2}^{n} E\left(L_{i} \mid L_{1}\right)\right)
$$

\subsection{Case 1: Low Correlation Between Future Calendar Years}

Assume there is very little correlation in the calendar year loss distributions (Table 2).

Since the correlation between $L_{i}$ and $L_{1}$ is close to 0 (Table 2), then $E\left(L_{i} \mid L_{1}\right) \approx E\left(L_{i}\right)$. It therefore follows that:

$$
\operatorname{Var}\left(E\left[L_{U L t} \mid L_{1}\right]\right) \approx \operatorname{Var}\left(L_{1}\right)
$$

The forecast table with means, standard deviations, and expected variation conditional on the next calendar year's data are shown in Table 3.

In Table 3, the variation in the next calendar year's loss, 796, 830, is close to the total variation in the expected ultimate, conditional on the next calendar year's data, 807, 822 .

When the correlation between calendar years is close to 0 , the variance of the sum of the conditional expectations, $\operatorname{Var}\left(\sum_{(i=2)}^{n} E\left(L_{i} \mid L_{1}\right)\right)$, is close to 0 . 
Table 2. Case 1: low future calendar year correlations

\begin{tabular}{llllllllllll}
\hline \hline & \multicolumn{7}{c}{ Calendar Year Total Reserve Distribution Correlations } \\
\cline { 2 - 12 } Calendar Year & 1988 & 1989 & 1990 & 1991 & 1992 & 1993 & 1994 & 1995 & 1996 & 1997 \\
\hline 1988 & 1.0000 & 0.0031 & 0.0039 & 0.0046 & 0.0053 & 0.0058 & 0.0061 & 0.0061 & 0.0056 & 0.0044 \\
1989 & 0.0031 & 1.0000 & 0.0056 & 0.0067 & 0.0078 & 0.0086 & 0.0091 & 0.0090 & 0.0083 & 0.0065 \\
1990 & 0.0039 & 0.0056 & 1.0000 & 0.0090 & 0.0105 & 0.0115 & 0.0122 & 0.0122 & 0.0112 & 0.0088 \\
1991 & 0.0046 & 0.0067 & 0.0090 & 1.0000 & 0.0131 & 0.0144 & 0.0153 & 0.0153 & 0.0140 & 0.0110 \\
1992 & 0.0053 & 0.0078 & 0.0105 & 0.0131 & 1.0000 & 0.0171 & 0.0182 & 0.0181 & 0.0167 & 0.0130 \\
1993 & 0.0058 & 0.0086 & 0.0115 & 0.0144 & 0.0171 & 1.0000 & 0.0205 & 0.0203 & 0.0186 & 0.0146 \\
1994 & 0.0061 & 0.0091 & 0.0122 & 0.0153 & 0.0182 & 0.0205 & 1.0000 & 0.0219 & 0.0201 & 0.0158 \\
1995 & 0.0061 & 0.0090 & 0.0122 & 0.0153 & 0.0181 & 0.0203 & 0.0219 & 1.0000 & 0.0205 & 0.0162 \\
1996 & 0.0056 & 0.0083 & 0.0112 & 0.0140 & 0.0167 & 0.0186 & 0.0201 & 0.0205 & 1.0000 & 0.0152 \\
1997 & 0.0044 & 0.0065 & 0.0088 & 0.0110 & 0.0130 & 0.0146 & 0.0158 & 0.0162 & 0.0152 & 1.0000 \\
\hline \hline
\end{tabular}

Table 3. Case 1: forecast table and contribution to variation in mean ultimate (VMU)

\begin{tabular}{|c|c|c|c|c|c|}
\hline \multirow[b]{2}{*}{ Calendar Year } & \multirow[b]{2}{*}{ Mean Outstanding } & \multirow[b]{2}{*}{ SD } & \multicolumn{2}{|c|}{ Conditional on Next Calendar Periods } & \multirow{2}{*}{$\begin{array}{l}\text { Contribution to } \\
\text { Variation in VMU }\end{array}$} \\
\hline & & & $\operatorname{VE}[\operatorname{Var}[$ Outs|Data]]] & $\mathrm{SD}[\mathrm{E}[$ Outs|Data] $]$ & \\
\hline 1988 & $2,271,475$ & 796,830 & 0 & 796,830 & 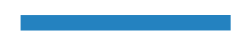 \\
\hline 1989 & $1,738,278$ & 618,518 & 618,511 & 2,935 & $\mathbf{I}$ \\
\hline 1990 & $1,295,092$ & 460,371 & 460,362 & 2,887 & $\mathbf{I}$ \\
\hline 1991 & 970,534 & 345,194 & 345,184 & 2,683 & $\mathbf{I}$ \\
\hline 1992 & 736,019 & 264,090 & 264,079 & 2,414 & $\mathbf{I}$ \\
\hline 1993 & 572,207 & 212,380 & 212,370 & 2,147 & $\mathbf{I}$ \\
\hline 1994 & 442,367 & 172,743 & 172,733 & 1,863 & $\mathbf{I}$ \\
\hline 1995 & 333,198 & 143,302 & 143,294 & 1,548 & $\mathbf{I}$ \\
\hline 1996 & 222,351 & 113,518 & 113,513 & 1,132 & I \\
\hline 1997 & 111,577 & 78,963 & 78,961 & 620 & $\mathbf{I}$ \\
\hline Total & $8,693,097$ & $1,266,196$ & 975,026 & 807,822 & \\
\hline
\end{tabular}

The contribution of the variation in the mean losses, $L_{2} \ldots L_{n}$ conditional on $L_{1}$, to the VMU is negligible compared to the variation in $L_{1}$ (Table 3 ).

\subsection{Case 2: High Correlation Between Future Calendar Years}

Consider high positive correlation between calendar year loss distributions (Table 4).

The importance of the covariance terms as contributors to the total variation increases as the correlation increases.

$$
\begin{gathered}
\operatorname{Var}\left(E\left[L \mid L_{1}\right]\right)=\operatorname{Var}\left(L_{1}+\sum_{i=2}^{n} E\left(L_{i} \mid L_{1}\right)\right) \\
=\operatorname{Var}\left(L_{1}\right)+2 \cdot \operatorname{cov}\left(L_{1}, \sum_{i=2}^{n} E\left(L_{i} \mid L_{1}\right)\right)+\operatorname{Var}\left(\sum_{i=2}^{n} E\left(L_{i} \mid L_{1}\right)\right)
\end{gathered}
$$


Table 4. Case 2: high future calendar year correlations

\begin{tabular}{lccccccccccc}
\hline \hline & \multicolumn{7}{c}{ Calendar Year Total Reserve Distribution Correlations } \\
\cline { 2 - 13 } Calendar Year & 1988 & 1989 & 1990 & 1991 & 1992 & 1993 & 1994 & 1995 & 1996 & 1997 \\
\hline 1988 & 1.0000 & 0.9599 & 0.9595 & 0.9560 & 0.9514 & 0.9456 & 0.9389 & 0.9313 & 0.9225 & 0.9118 \\
1989 & 0.9599 & 1.0000 & 0.9862 & 0.9849 & 0.9320 & 0.9776 & 0.9721 & 0.9654 & 0.9574 & 0.9476 \\
1990 & 0.9595 & 0.9862 & 1.0000 & 0.9930 & 0.9915 & 0.9884 & 0.9840 & 0.9785 & 0.9715 & 0.9627 \\
1991 & 0.9560 & 0.9849 & 0.9930 & 1.0000 & 0.9955 & 0.9936 & 0.9905 & 0.9861 & 0.9803 & 0.9726 \\
1992 & 0.9514 & 0.9820 & 0.9915 & 0.9955 & 1.0000 & 0.9955 & 0.9947 & 0.9915 & 0.9868 & 0.9803 \\
1993 & 0.9456 & 0.9776 & 0.9884 & 0.9936 & 0.9965 & 1.0000 & 0.9972 & 0.9951 & 0.9916 & 0.9362 \\
1994 & 0.9389 & 0.9721 & 0.9840 & 0.9905 & 0.9947 & 0.9972 & 1.0000 & 0.9973 & 0.9950 & 0.9910 \\
1995 & 0.9313 & 0.9654 & 0.9785 & 0.9861 & 0.9915 & 0.9951 & 0.9973 & 1.0000 & 0.9973 & 0.9946 \\
1996 & 0.9225 & 0.9574 & 0.9715 & 0.9803 & 0.9868 & 0.9916 & 0.9950 & 0.9973 & 1.0000 & 0.9965 \\
1997 & 0.9118 & 0.9476 & 0.9627 & 0.9726 & 0.9303 & 0.9862 & 0.9910 & 0.9946 & 0.9965 & 1.0000 \\
\hline \hline & & & & & & & & & & 0.996 \\
\hline
\end{tabular}

Table 5. Case 2: forecast table and contribution to variation in mean ultimate (VMU)

\begin{tabular}{|c|c|c|c|c|c|}
\hline \multirow[b]{2}{*}{ Calendar Year } & \multirow[b]{2}{*}{ Mean Outstanding } & \multirow[b]{2}{*}{ SD } & \multicolumn{2}{|c|}{ Conditional on Next Calendar Periods } & \multirow{2}{*}{$\begin{array}{l}\text { Contribution to } \\
\text { Variation in VML }\end{array}$} \\
\hline & & & VE[Var[OutsIData]]] & $\mathrm{SD}[\mathrm{E}[$ OutsIData $]]$ & \\
\hline 1988 & $1,863,279$ & 110,997 & 0 & 110,997 & 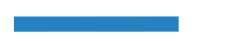 \\
\hline 1989 & $1,431,551$ & 155,420 & 33,443 & 151,779 & \\
\hline 1990 & $1,073,424$ & 170,458 & 32,943 & 167,244 & \\
\hline 1991 & 811,554 & 170,229 & 31,865 & 167,221 & 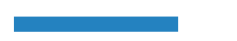 \\
\hline 1992 & 622,395 & 162,661 & 30,183 & 159,836 & - \\
\hline 1993 & 490,446 & 153,724 & 28,652 & 151,030 & - \\
\hline 1994 & 385,174 & 141,102 & 26,450 & 138,601 & 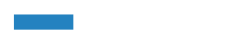 \\
\hline 1995 & 295,338 & 124,002 & 23,377 & 121,778 & - \\
\hline 1996 & 201,097 & 95,579 & 18,311 & 93,809 & घ \\
\hline 1997 & $103,, 216$ & 55,039 & 10,868 & 53,955 & I \\
\hline Total & $7,277,474$ & $1,326,688$ & 217,202 & $1,308,787$ & \\
\hline
\end{tabular}

Forecast scenario: Case 2

In this case, the contribution of $2 \cdot \operatorname{cov}\left(L_{1}, \sum_{i=2}^{n} E\left(L_{i} \mid L_{1}\right)\right)$ and $\operatorname{Var}\left(\sum_{i=2}^{n} E\left(L_{i} \mid L_{1}\right)\right)$ dominate the contribution of $\operatorname{Var}\left(L_{1}\right)$ (Table 5$)$ to the VMU.

In Table 5, the variation in the next calendar year's loss, 110, 997, is a small fraction of the total variation in the expected ultimate conditional on the next calendar year's data, 1, 308, 787. Taking into consideration the correlation between the distributions, the losses in $L_{1}$ contribute to about $15 \%$ of the variation in the VMU compared to $99.99 \%$ of the variation in Case 1.

\section{0. $V M U_{99.5 \%}$ Versus $S C R^{2}$}

The $99.5^{\text {th }}$ percentile of the VMU is usually not the same as the value of $S C R^{2}$. These measures will only be similar if the correlations between future calendar year loss distributions approach 1 (see section 9.2). 
If the correlations between future calendar years are close to one, then:

$$
S C R^{2} \approx V M U_{99.5}
$$

$S C R^{2}$ and $V M U_{99.5}$ are approximately the same.

When the correlations are high, looking at the percentile (99.5) of the sum of the changes is close to taking the sum of the $99.5^{\text {th }}$ percentiles for each year. That is, it is closer to taking the V@R $R_{99.5}$ of $L_{U l t}$.

If there is no parameter uncertainty then the correlation between calendar periods is 0 . That is, $E\left[L_{i} \mid L_{1}\right]=E\left[L_{i}\right]$ and:

$$
S C R^{2}<<V M U_{99.5}
$$

In the case of $S C R^{2}$, only the first year is in distress and subsequent $\triangle B E L s$ are not likely to be at the same percentile at the same time.

\section{Solvency II Standard Formula and SCR}

In the Solvency II context, the QIS5 SCR standard formula is based on $\mathrm{E}(\mathrm{L})$ and $\operatorname{Var}(\mathrm{CDR})$ $(=\operatorname{Var}(\mathrm{VMU}))$ (European Commission, 2010).

The V@ $R_{99.5 \%}(V M U)$ is one of the approximations for SCR based on the standard formula (European Commission, 2010). We denote this SCR as $S C R^{4}$. Since the distress in the next calendar year is not explicitly calculated, it is effectively assumed that $V @ R_{99.5 \%}(V M U)$ corresponds to being in distress in the first year and having sufficient capital to restore the means of the Economic Balance Sheet (RMs are ignored).

However, the recommended approach in the standard formula is to fit a log-normal to the mean (Provision of Claims Outstanding $=E(L))$ and Variance $(\operatorname{Var}(\mathrm{CDR}))$. The log-normal distribution is not necessarily a good proxy for the distribution of VMU. (See QIS5 technical specifications European Commission (2010), paragraph SCR.9.18.) This approximation to $S C R^{4}$ we denote $S C R^{4 \%}$.

$S C R^{4 *}$ is not related to $S C R^{1}, S C R^{2}, S C R^{3}$ nor even to the distribution of $V M U$ and therefore to $S C R^{4}$. The differences between $S C R^{4}$ and any of the other SCR calculations are model dependent (and data dependent).

Consider the two cases from section 9. In the situation where future calendar year correlations are close to 0 (Case 1), $S C R^{1}, S C R^{2}, S C R^{3}$, and $S C R^{4}$ are about the same (Table 6) - they are within expected statistical variation. The lognormal distribution approximation, $S C R^{4 *}$, produces a much lower estimate - in fact lower than the $99.5^{\text {th }}$ percentile of the first calendar year $\left(S C R^{1}\right)$. The company would not even be able to pay for the losses up to the $99.5^{\text {th }}$ percentile even if the model was completely correct.

Table 6. SCR comparison for Cases 1 and 2

\begin{tabular}{lllllr}
\hline \hline Case & $S C R^{1}$ & $S C R^{2}$ & $S C R^{3}$ & $S C R^{4}$ & $S C R^{4 *}$ \\
\hline 1 & $3.18 \mathrm{M}$ & $3.20 \mathrm{M}$ & $3.24 \mathrm{M}$ & $3.21 \mathrm{M}$ & $2.29 \mathrm{M}$ \\
2 & $0.30 \mathrm{M}$ & $3.69 \mathrm{M}$ & $3.56 \mathrm{M}$ & $3.78 \mathrm{M}$ & $4.05 \mathrm{M}$ \\
\hline \hline
\end{tabular}


Table 7. Solvency II Capital Requirement (SCR) comparison for Cases 1 and 2

\begin{tabular}{|c|c|c|}
\hline $\begin{array}{l}\text { SCR } \\
\text { Estimate }\end{array}$ & Key Assumptions & Properties \\
\hline$S C R^{1}$ & $\begin{array}{l}\text { No parameter uncertainty; implies correlations } \\
\text { between future calendar year loss distributions } \\
\text { are } 0\end{array}$ & $\begin{array}{l}\text { Process volatility inclusion ensures sufficient } \\
\text { capital to cover losses in the first calendar year }\end{array}$ \\
\hline$S C R^{2}$ & $\begin{array}{l}\text { Receiver of Risk if liabilities transferred does } \\
\text { not have to subscribe to Solvency II regulation }\end{array}$ & $\begin{array}{l}\text { Process volatility and parameter uncertainty } \\
\text { included. Fair value obtained for restoration } \\
\text { of mean estimates but not the Risk Margin. } \\
S C R^{2} \geq S C R^{1}\end{array}$ \\
\hline$S C R^{3}$ & $\begin{array}{l}\text { Receiver of liabilities subscribes to Solvency II } \\
\text { regulation }\end{array}$ & $\begin{array}{l}\text { Economic Balance Sheet can be fully restored after } \\
\text { a distress event. Usually } S C R^{3} \geq S C R^{2}\end{array}$ \\
\hline$S C R^{4}$ & $\begin{array}{l}\text { All future loss distributions have a correlation } \\
\text { of } 1 \text { with the losses in the first calendar year }\end{array}$ & $\begin{array}{l}\text { The future correlation assumption almost } \\
\text { guarantees } S C R^{4} \geq S C R^{3}\end{array}$ \\
\hline$S C R^{4 *}$ & $\begin{array}{l}\text { Distribution of } S C R^{4} \text { is log-normal with mean } \\
E(L) \text { and variance }(\operatorname{Var}(C D R))\end{array}$ & $\begin{array}{l}\text { The distribution of } S C R^{4} \text { is not likely to be log- } \\
\text { normal and the value of the estimator is unknown }\end{array}$ \\
\hline
\end{tabular}

However, when the parameter uncertainty and correlations between the loss distributions by calendar year are high (Case 2), $S C R^{4 *}$ well exceeds $S C R^{4}>S C R^{2}>S C R^{3}>>S C R^{1}$ (Table 6).

Note that in the second example, $S C R^{2}>S C R^{3}$ as the $V @ R_{99.5}$ requirements decrease, even in the case of distress, as improved knowledge of the parameter actually reduces the $V @ R$ in subsequent calendar years. The calculation of $S C R^{3}$ takes advantage of this knowledge whereas $S C R^{2}$ is oblivious.

\section{Summary}

Four methods of estimating the appropriate SCR were compared along with an approximation. The calculation method most consistent with the Solvency II directives is the $S C R^{3}$ estimate as presented in Munroe et al. (2015). This calculation is consistent with the Solvency II directives and also ties in with the way one would calculate RMs.

The simpler calculations, $S C R^{1}$ and $S C R^{2}$, usually do not provide sufficient capital to restore the Economic Balance Sheet should a distress event occur. Estimation of required risk capital is reasonable only in very particular conditions.

All measures of SCR in Table 7 assume the model used to estimate the loss distributions is correct.

The standard formula calculation for SCR based on the distribution of the VMU, SCR ${ }^{4}$, is too conservative when correlations are high. The approximation to the distribution of VMU using a lognormal distribution assumption to $E(L)$ and $\operatorname{Var}(\mathrm{VMU})$ was shown to be too conservative (section 11) when correlations were high, and far too optimistic when correlations were low. The lognormal distribution approximation for $S C R^{4}, S C R^{4^{*}}$, is a very poor estimator of $S C R^{4}$.

\section{Acknowledgements}

The authors thank their colleagues, David Odell, Nikolai Volodin, Serge Sandler, and Glen Barnett, for comments which helped improve this paper. The feedback from anonymous reviewers was also much appreciated. 


\section{References}

England, P. (2011). Solvency II: reserving risk, risk margins and technical provisions, available at https://cas.confex.com/cas/clrs11/webprogramucas/Presentation/Session4365/Peter\%20England \%20-\%20Solvency\%20II\%20-\%20Reserving\%20Risk, \%20Risk\%20Margins \%20and\%20 Technical\%20Provisions.pdf (accessed 15 September 2011).

European Commission (2007). Proposal for the Solvency II directive (COM/2007/0361), available at http://eur-lex.europa.eu/LexUriServ/LexUriServ.do?uri=COM:2007:0361:FIN:EN:PDF (accessed 4 February 2010).

European Commission (2009a). Final CEIOPS' advice for level 2 implementing measures on Solvency II: Technical provisions - article 86 (d) calculation of the risk margin, available at https://eiopa.europa. eu/CEIOPS-Archive/Documents/Advices/CEIOPS-L2-Final-Advice-on-TP-Risk-Margin.pdf (accessed 9 February 2010).

European Commission (2009b). Solvency II directive (2009/138/EC), available athttp://eur-lex. europa.eu/LexUriServ/LexUriServ.do?uri=CELEX:32009L0138:EN:NOT (accessed 9 February 2010).

European Commission (2010). QIS5 technical specifications, available athttp://ec.europa.eu/internal_market/insurance/docs/solvency/qis5/201007/technical_specifications_en.pdf (accessed 28 September 2011).

Merz, M. \& Wüthrich, M.V. (2008). Modelling the claims development result for solvency purposes. CAS E-Forum, 2008, 542-568.

Munroe, D., Odell, D., Sandler, S. \& Zehnwirth, B. (2015). A solution for Solvency II quantitative requirements modeling with long-tail liabilities. North American Actuarial Journal, 19(2), 79-93.

Ohlsson, E. \& Lauzeningks, J. (2009). The one-year non-life insurance risk. Insurance: Mathematics and Economics, 45, 203-208.

Swiss Federal Office of Private Insurance (2004). White paper of the Swiss Solvency Test, available at https://www.finma.ch/FinmaArchiv/bpv/download/e/WhitePaperSST_en.pdf (accessed 6 October 2017). 